\title{
What is the impact of radical hysterectomy on endometrial cancer with cervical involvement?
}

\author{
Salim Abraham Barquet-Muñoz ${ }^{1}$, David Cantú-de-León 1,2,3 ${ }^{1}$ Antonio Bandala-Jacques ${ }^{2,3}$, Aarón González-Enciso ${ }^{4}$, \\ David Isla-Ortiz', Diddier Prada ${ }^{2,3,5}$, Luis A. Herrera ${ }^{2,3,6}$ and R. A. Salcedo-Hernández ${ }^{1 *}$
}

\begin{abstract}
Background: When endometrial carcinoma invades the cervical stroma, overall survival and disease-free survival decrease. However, it is still controversial whether patients in suspected stage II should be treated with radical hysterectomy. The goal of this study is to describe the role of radical hysterectomy in patients with endometrial carcinoma and cervical involvement.

Methods: This was a retrospective cohort study were a total of 239 patients with endometrial carcinoma with cervical involvement from Mexico City's National Cancer Institute were divided according to the type of hysterectomy, and the outcomes were compared using statistical analysis.

Results: The 5-year overall survival was $75.76 \%$ for the simple hysterectomy group and $89.19 \%$ for the radical hysterectomy group, without achieving statistical significance. The 5-year disease-free survival was $72.95 \%$ for the simple hysterectomy group and $64.31 \%$ for the radical hysterectomy group, without achieving statistical significance. Radicality was associated with longer surgical times, intraoperative complications, and bleeding over $500 \mathrm{ml}$.

Conclusions: In patients with endometrial carcinoma with cervical involvement, radical hysterectomy does not improve prognosis or alter adjuvant therapy.
\end{abstract}

Keywords: Endometrial neoplasms, Hysterectomy, Carcinoma, Endometrioid

\section{Background}

Endometrial carcinoma invades the cervical stroma in 5$10 \%$ of cases [1]. When there is exclusive cervical invasion, defined as International Federation of Gynecology and Obstetrics (FIGO) stage II, the 5-year overall survival decreases to $75 \%$, compared to $88 \%$ for stage I [2]. It is still controversial whether patients in suspected stage II should be treated with radical hysterectomy [3, 4]. The goals of this surgical management are to obtain an optimal

\footnotetext{
* Correspondence: rosasalher@gmail.com

'Departamento de Ginecología, Instituto Nacional de Cancerología, San Fernando 22, Tlalpan, 14080 Mexico City, Mexico

Full list of author information is available at the end of the article
}

cytoreduction and identify parametrial involvement, with the consequent change in clinical staging, prognosis, and need for adjuvancy [4]. It should be noted that radical hysterectomy carries a risk of complications that could delay adjuvancy [5]. Additionally, cervical involvement could be associated with other poor prognostic factors, such as lymphovascular invasion, unfavorable histologies, deep myometrial invasion, and ovarian and lymph node involvement $[2,6,7]$. This brings to question the therapeutic role of radical hysterectomy in patients with endometrial carcinoma with cervical involvement.

(c) The Author(s). 2020 Open Access This article is licensed under a Creative Commons Attribution 4.0 International License, which permits use, sharing, adaptation, distribution and reproduction in any medium or format, as long as you give appropriate credit to the original author(s) and the source, provide a link to the Creative Commons licence, and indicate if changes were made. The images or other third party material in this article are included in the article's Creative Commons licence, unless indicated otherwise in a credit line to the material. If material is not included in the article's Creative Commons licence and your intended use is not permitted by statutory regulation or exceeds the permitted use, you will need to obtain permission directly from the copyright holder. To view a copy of this licence, visit http://creativecommons.org/licenses/by/4.0/ The Creative Commons Public Domain Dedication waiver (http://creativecommons.org/publicdomain/zero/1.0/) applies to the data made available in this article, unless otherwise stated in a credit line to the data. 
The goal of this study is to describe the role of radical hysterectomy in patients with endometrial carcinoma and cervical involvement, independent of clinical stage.

\section{Methods}

This was a retrospective cohort study with patients treated at Mexico City's National Cancer Institute between January 2005 and December 2018. The data were obtained from the clinical files of the electronic records of patients who met inclusion criteria, after which a database was created and analyzed.

The inclusion criteria were patients with a diagnosis of endometrial carcinoma with involvement of cervical stroma suspected preoperatively by imaging (computed tomography (CT) or magnetic resonance imaging (MRI)) or by biopsy, confirmed by the Pathology Department, and treated with hysterectomy. Patients not undergoing hysterectomy, those who received neoadjuvant chemotherapy, those with two primary malignancies, and those with insufficient data for analysis were excluded. All hysterectomies were performed by gynecologic oncologists or by oncologic surgeons with experience in gynecologic cancer. For patients requiring some type of adjuvant treatment, the radiotherapy schemes were an external beam radiotherapy regimen of $45 \mathrm{~Gy}$ in 25 fractions, high-dose-rate brachytherapy of 24 Gy in 4 sessions, or low-dose-rate brachytherapy from 30 to 35 Gy. For patients who were prescribed chemotherapy, the scheme used more frequently was carboplatin with paclitaxel for 4 to 6 cycles at the discretion of the medical oncologist.

Clinical, surgical, treatment, and pathological variables were identified. A pathology review was performed by an oncologic pathologist. The patients were divided into two groups, the first contained patients undergoing simple hysterectomy and the second contained patients undergoing radical hysterectomy. Overall survival was defined as the time period between diagnosis and death or the date last seen. Disease-free survival was defined as the time period between surgery and recurrence or the date last seen.

For the descriptive analysis, central tendency measures were used. The median and interquartile range were used for continuous variables, and absolute and relative frequencies were used for categorical variables. For the comparative analysis, Wilcoxon's rank-sum test, chisquared, or Fisher's exact test were used depending on the analyzed variable. Logistic regressions were used to obtain odds ratios and establish factors associated with radical hysterectomy. Survival curves were generated with the Kaplan-Meier estimator and compared with the log-rank test. Univariate and multivariate analyses were performed with Cox regression. Statistical significance was defined as a $p$ value $<0.05$. Statistical analysis was performed with STATA software, version 13.0 (College Station, TX). This study was approved by the Institutional Review Board (Comité de Investigación y Ética) with approval reference CEI051/16.

\section{Results}

Out of 1014 identified patients with endometrial carcinoma, 239 (23.6\%) met all inclusion criteria and were included in the analysis. The median age was 55.64 (interquartile range [IQR] 47.2-63.5) years, and the median weight was 67 (IQR 59-79.8) kg. The most frequent histology was endometrioid adenocarcinoma, with 177 (74.06\%) cases. The median tumor size was 12 (IQR 5.565) $\mathrm{mm}$, and there were $110(46.03 \%)$ grade 2 cases. A total of $165(74.32 \%)$ cases had lymphovascular invasion. Additionally, the median cervical stromal invasion depth was 6 (IQR 3-12.5) $\mathrm{mm}$, with a depth invasion/stromal rate of 0.5 (IQR $0.25-0.92$ ). Pelvic lymphadenectomy was performed on 165 (69\%) patients, of which 70 (42.42\%) had lymphatic disease. Likewise, 135 (56.5\%) patients underwent para-aortic lymphadenectomy, of which 40 (29.63\%) had lymph node metastasis. Regarding clinical stage, 98 (41\%) patients were diagnosed with stage II disease, and 95 (39.7\%) were diagnosed with stage III disease. A total of $182(76.2 \%)$ patients underwent simple hysterectomy, and 39 (16.32\%) underwent radical hysterectomy. Out of the patients who received adjuvant treatment, 153 (64.0\%) received external beam radiotherapy, 165 (69.0\%) received brachytherapy, and 129 (53.97\%) received chemotherapy (Table 1). Of this group that received adjuvant treatment, 109 (45.6\%) received any type of radiotherapy and chemotherapy, and 97 (40.6\%) received only brachytherapy with chemotherapy.

In the comparative analysis between the types of hysterectomies, a statistically significant difference was found regarding histology, in which there was a higher percentage of histologies with poor prognosis in the radical hysterectomy group ( $23 \%$ vs. $41 \%, p=0.007$ ). The radical hysterectomy group had a higher median depth of cervical stromal invasion (10.5 mm [IQR 5-15] vs. $5 \mathrm{~mm}$ [IQR 3-12], $p=0.005$ ) and a higher depth of invasion/thickness rate $(0.52$ [IQR $0.4-0.87$ ] vs. 0.48 [IQR 0.25-0.67]) than the simple hysterectomy group. No statistically significant difference was found in the other variables, including histologic grade, lymphovascular invasion, depth of myometrial involvement, lymph node disease, and adjuvancy. Likewise, the percentages of recurrence and death were similar in both groups (Table 1).

Regarding the surgical variables, there were a total of 18 (7.53\%) intraoperative complications and 9 (3.77\%) reinterventions. The intraoperative complications were as follows: 5 (27.8\%) bladder injuries, 5 (27.8\%) accidental injuries to a blood vessel, 4 (22.2\%) intestinal injuries, 
Table 1 Comparison according to the type of hysterectomy in patients with endometrial carcinoma with cervical involvement $(N=$ 239)

\begin{tabular}{|c|c|c|c|c|}
\hline & SH, $200(83.68 \%)$ & $\mathrm{RH}, 39(16.32 \%)$ & Total, 239 & $p$ \\
\hline Age, years ${ }^{*}$ & $55.42(46.9-63.9)$ & $56.55(48.7-62.4)$ & $55.64(47.2-63.5)$ & 0.756 \\
\hline Weight, kg ${ }^{¥}$ & 67 (59.8-79.9) & $66(57-79)$ & 7 (59-79.8) & 0.643 \\
\hline $\mathrm{BMI}^{*}$ & $28.55(25.2-33.8)$ & $27.83(24.4-32.5)$ & $28.51(25.1-33.3)$ & 0.600 \\
\hline Positive cytology $y^{\S}$ & $82(41)$ & $21(53.85)$ & $103(43.10)$ & 0.138 \\
\hline \multicolumn{5}{|l|}{ Histology ${ }^{\S}$} \\
\hline Endometrioid & $154(77)$ & $23(58.97)$ & $177(74.06)$ & \multirow[t]{5}{*}{0.007} \\
\hline Serous papillary & $15(7.5)$ & $6(16.38)$ & $21(8.79)$ & \\
\hline Clear cell & $4(2.0)$ & $1(2.56)$ & $5(2.09)$ & \\
\hline Mixed & $26(13.0)$ & $6(15.38)$ & 32 (13.39) & \\
\hline Carcinosarcoma & $1(0.5)$ & $3(7.69)$ & $4(1.67)$ & \\
\hline Tumor size, $\mathrm{mm}^{¥}$ & $15(5.3-70.0)$ & $5(6-50)$ & $12(5.5-65.0)$ & 0.349 \\
\hline \multicolumn{5}{|l|}{ Grade $^{\S}$} \\
\hline G1 & $9(4.59)$ & $4(10.26)$ & $13(5.44)$ & \multirow[t]{4}{*}{0.130} \\
\hline G2 & $96(48.0)$ & $14(35.90)$ & $110(46.03)$ & \\
\hline G3 & 39 (19.50) & $5(12.82)$ & $44(18.41)$ & \\
\hline Poor prognostic histology & $56(28)$ & $16(41.03)$ & $72(30.13)$ & \\
\hline Lymphovascular invasion ${ }^{\S}$ & $134(72.43)$ & 31 (83.78) & $165(74.32)$ & 0.183 \\
\hline \multicolumn{5}{|l|}{ Myometrial involvement ${ }^{\S}$} \\
\hline Superficial & $5(2.50)$ & $1(2.56)$ & $6(2.51)$ & \multirow[t]{4}{*}{0.994} \\
\hline$<50 \%$ & $52(26.00)$ & $10(25.64)$ & $62(25.94)$ & \\
\hline$>50 \%$ & $125(62.50)$ & $25(64.10)$ & $150(62.76)$ & \\
\hline NA & $18(9.0)$ & $3(7.69)$ & $21(8.79)$ & \\
\hline Depth of invasion, $\mathrm{mm}^{*}$ & $5(3-12)$ & $10.5(5-15)$ & $6(3-12.5)$ & 0.005 \\
\hline Depth invasion/thickness rate ${ }^{¥}$ & $0.48(0.25-0.67)$ & $0.52(0.4-0.87)$ & $0.5(0.25-0.92)$ & 0.028 \\
\hline Ovarian involvement ${ }^{\S}$ & $35(17.50)$ & $7(17.95)$ & $42(17.57)$ & 0.946 \\
\hline Parametrial involvement ${ }^{\S}$ & $9(4.50)$ & 7 (17.95) & $16(6.69)$ & 0.002 \\
\hline Uterine serosa involvement ${ }^{\S}$ & $18(9.0)$ & $5(12.82)$ & $23(9.62)$ & 0.459 \\
\hline Pelvic lymph node involvement, $n=165^{\S}$ & $55(41.04)$ & $15(48.39)$ & $70(42.42)$ & 0.456 \\
\hline Para-aortic lymph node involvement, $n=135^{\S}$ & $34(31.78)$ & $6(21.43)$ & $40(29.63)$ & 0.286 \\
\hline \multicolumn{5}{|l|}{ Stage $^{\S}$} \\
\hline ॥ & $87(43.50)$ & $11(28.21)$ & $98(41.00)$ & \multirow[t]{4}{*}{0.124} \\
\hline III & $73(36.50)$ & $22(56.41)$ & $95(39.75)$ & \\
\hline IV & $31(15.5)$ & $4(10.26)$ & $35(14.64)$ & \\
\hline NA & $9(4.50)$ & $2(5.13)$ & $11(4.60)$ & \\
\hline Any radiotherapy ${ }^{\S \pm}$ & $150(75.00)$ & $32(82.05)$ & $182(76.2)$ & 0.345 \\
\hline Brachytherapy & $135(67.50)$ & $30(76.92)$ & $165(69.04)$ & 0.244 \\
\hline External beam radiotherapy & $124(62)$ & $29(74.36)$ & $153(64.02)$ & 0.141 \\
\hline Chemotherapy $^{\S}$ & $107(53.50)$ & $22(56.41)$ & $129(53.97)$ & 0.739 \\
\hline Recurrence ${ }^{\S}$ & $46(23.00)$ & $11(28.21)$ & $57(23.85)$ & 0.485 \\
\hline Death $^{\S}$ & $35(17.50)$ & $5(12.82)$ & $40(16.74)$ & 0.474 \\
\hline
\end{tabular}

SH simple hysterectomy, $R H$ radical hysterectomy, $B M I$ body mass index, $N A$ not applicable/unavailable

${ }^{¥}$ Median (interquartile range), statistical analysis: sum of ranks

${ }^{\S}$ Absolute value (relative analysis), statistical analysis: chi-squared

${ }^{ \pm}$Low-dose-rate brachytherapy, high-dose-rate brachytherapy, and external beam radiotherapy 
$2(11.1 \%)$ ureteral injuries, and $2(11.11 \%)$ injuries to a nerve. Of the reinterventions, $3(33.33 \%)$ were due to bleeding, 2 (22.22\%) were due to gastrointestinal perforation, and $4(44.44 \%)$ were due to the presence of accumulated fluid. The surgical variables associated with radical hysterectomy were para-aortic lymphadenectomy (OR 2.21, 95\% CI 1.04-4.04, $p=0.038$ ), longer surgical procedure duration (OR 1.001, 95\% CI 1.0007-1.008, $p$ $=0.020)$, intraoperative complications (OR 2.85, 95\% CI $1.01-8.12, p=0.050$ ), and bleeding over $500 \mathrm{ml}$ (OR $2.23,95 \%$ CI $1.07-4.68, p=0.033)$. There were no differences regarding the need for blood transfusion, need for reintervention, or type of approach (laparoscopic or laparotomy) (Table 2).

The median patient follow-up time was 30.8 months (IQR 14.74-53.37; min 1.63 and $\max 159.4$ months). The 5-year overall survival for all patients was $77.69 \%$ (95\% CI 69.9-83.7) (Fig. 1). The 5-year overall survival was $75.76 \%$ (95\% CI 67.03-82.47) for the simple hysterectomy group and $89.19 \%$ (95\% CI 69.57-96.46) for the radical hysterectomy group, without achieving statistical significance ( $p=0.513)$ (Fig. 2). The 5-year disease-free survival for the whole group was $71.65 \%$ (95\% CI 64.4476.66) (Fig. 3). The five-year disease-free survival was 72.95\% (95\% CI 65.16-79.28) for the simple hysterectomy group and $64.31 \%$ (95\% CI 43.41-79.17) for the radical hysterectomy group, without achieving statistical significance $(p=0.534)$ (Fig. 4).

In the multivariate analysis, the factors independently associated with overall survival (Table 3 ) were the presence of grade 3 or poor prognostic histology (HR 3.39, 95\% CI 1.16-9.92, $p=0.026$ ), receiving radiotherapy (HR 0.12, 95\% CI 0.004-0.39, $p<0.001$ ), and receiving chemotherapy (HR 3.74, 95\% CI 1.16-12.09, $p=0.027$ ). For disease-free survival (Table 4), the multivariate analysis found independent associations for tumor size (HR
$0.98,95 \%$ CI $0.96-0.99, p=0.031)$ and receiving radiotherapy (HR 0.12, 95\% CI 0.04-0.39, $p<0.001$ ). In the univariate analysis, radical hysterectomy was not associated with overall survival (HR 0.73, 95\% CI 0.29-1.87, $p$ $=0.515)$ or disease-free survival (HR 1.23, 95\% CI 0.642.38, $p=0.535$ ).

\section{Discussion}

There is controversy regarding the benefit radical hysterectomy provides to patients with endometrial carcinoma. Retrospective studies have not found a prognostic benefit for this procedure in patients with stage II endometrial carcinoma [8, 9]. Nevertheless, radical hysterectomy could be justified in cases in which the parametrium must be assessed for prognostic purposes and to guide adjuvancy [10]. The National Comprehensive Cancer Network (NCCN) guidelines recommend radical hysterectomy in cases with cervical involvement by image or biopsy to make decisions regarding the type of adjuvancy that will be offered [4]. The European Society for Medical Oncology (ESMO)-European Society of Gynaecological Oncology (ESGO)-European Society for Radiotherapy \& Oncology (ESTRO) consensus suggests that the goal of radical hysterectomy involves detecting negative margins and evaluating the type of adjuvancy [11].

In our study, radical hysterectomy did not improve overall survival or disease-free survival in patients with endometrial carcinoma with cervical involvement. The evidence regarding the role of radicality is controversial. In a study where 202 patients with cervical involvement were evaluated, the 5-year overall survival in the radical hysterectomy group was $86 \%$, compared to $61 \%$ in the simple hysterectomy group [10]. Likewise, in another study with 203 patients in stage II, the 5-year overall survival rates of patients who underwent radical and simple hysterectomies

Table 2 Surgical variables according to the type of hysterectomy in patients with endometrial carcinoma with cervical involvement $(N=239)$

\begin{tabular}{|c|c|c|c|c|c|c|}
\hline & Total & SH, 200 (83.68) & $\mathrm{RH}, 39$ (16.32) & OR & $95 \% \mathrm{Cl}$ & $p$ \\
\hline Pelvic lymphadenectomy ${ }^{\S}$ & $165(69.04)$ & $134(67.00)$ & $31(79.49)$ & 1.91 & $0.83-4.38$ & 0.128 \\
\hline Para-aortic lymphadenectomy ${ }^{\S}$ & 135 (56.49) & $107(53.50)$ & 28 (71.79) & 2.21 & $1.04-4.069$ & 0.038 \\
\hline Surgical time, $\min ^{*}$ & $210.5(160-295)$ & $210(152.5-280)$ & $238(205-335)$ & 1.001 & $1.0007-1.008$ & 0.020 \\
\hline Intraoperative complications ${ }^{\S}$ & $18(7.53)$ & $12(6.00)$ & $6(15.38)$ & 2.85 & $1.01-8.12$ & 0.050 \\
\hline Surgical bleeding, $\mathrm{ml}^{*}$ & $350(200-550)$ & $350(200-500)$ & $400(300-1000)$ & 1.003 & $0.99-1.0001$ & 0.165 \\
\hline Bleeding $>500 \mathrm{ml}^{\S}$ & $55(25.58)$ & $40(22.60)$ & $15(39.47)$ & 2.23 & $1.07-4.68$ & 0.033 \\
\hline Blood transfusion ${ }^{\S}$ & 65 (27.19) & $50(25)$ & $15(38.46)$ & 0.999 & $0.99-1.00$ & 0.136 \\
\hline Reintervention ${ }^{\S}$ & $9(3.77)$ & $7(3.50)$ & $2(5.13)$ & 1.49 & $0.29-7.46$ & 0.627 \\
\hline Laparoscopy ${ }^{\S}$ & $15(6.28)$ & $13(6.5)$ & $2(5.13)$ & 0.77 & $0.168-3.59$ & 0.747 \\
\hline
\end{tabular}

SH simple hysterectomy, $R H$ radical hysterectomy, OR odds ratio, 95\% Cl 95\% confidence interval

${ }^{¥}$ Median (interquartile range)

${ }^{\S}$ Absolute value (relative analysis) 


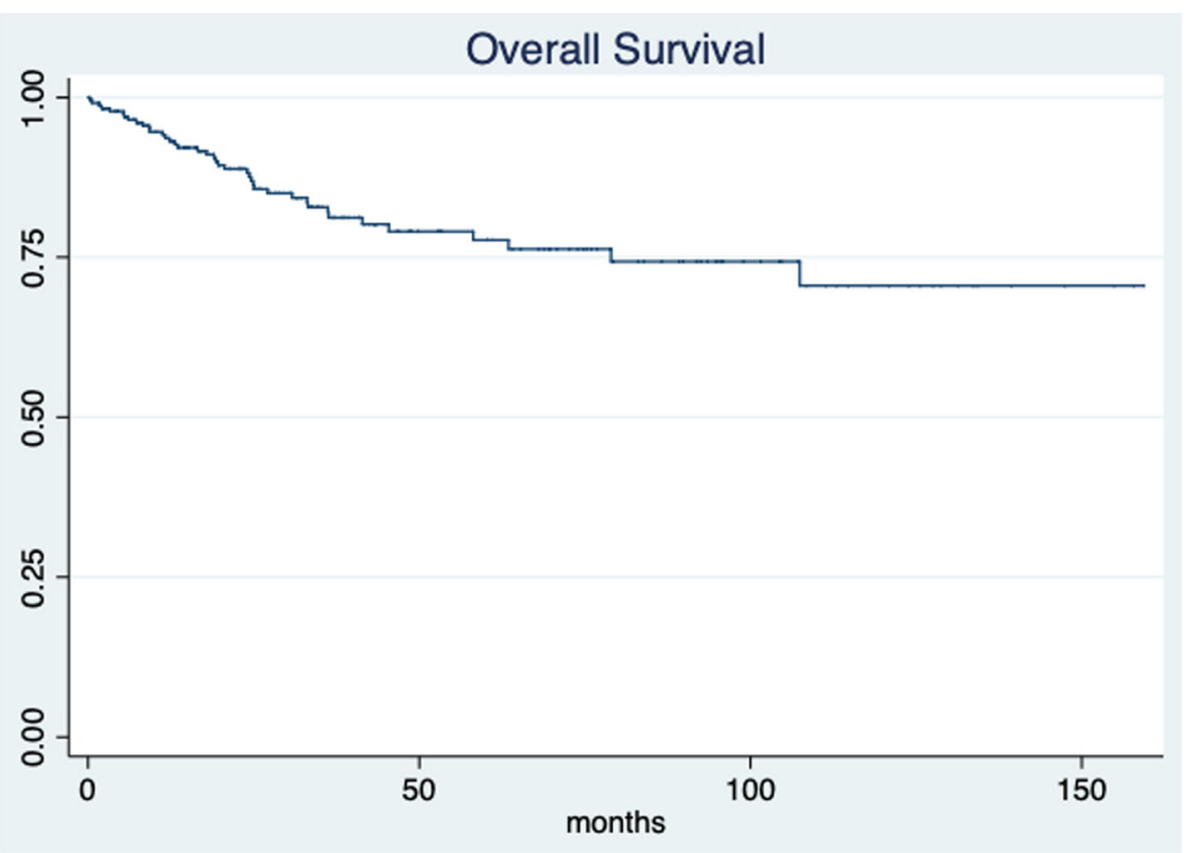

Fig. 1 Overall survival rate for all patients

were $94 \%$ and $79 \%$, respectively $(p<0.05)$. However, that study used the 1988 staging criteria, and not all patients received radiotherapy [2]. As to more recent evidence, studies have not suggested a benefit for radical hysterectomy in these patients. In the 2013
GOTIC study, which studied 300 patients with suspected cervical involvement, 74 underwent radical hysterectomy, 112 underwent modified radical hysterectomy, and 114 underwent simple hysterectomy, and no statistically significant difference was found in the

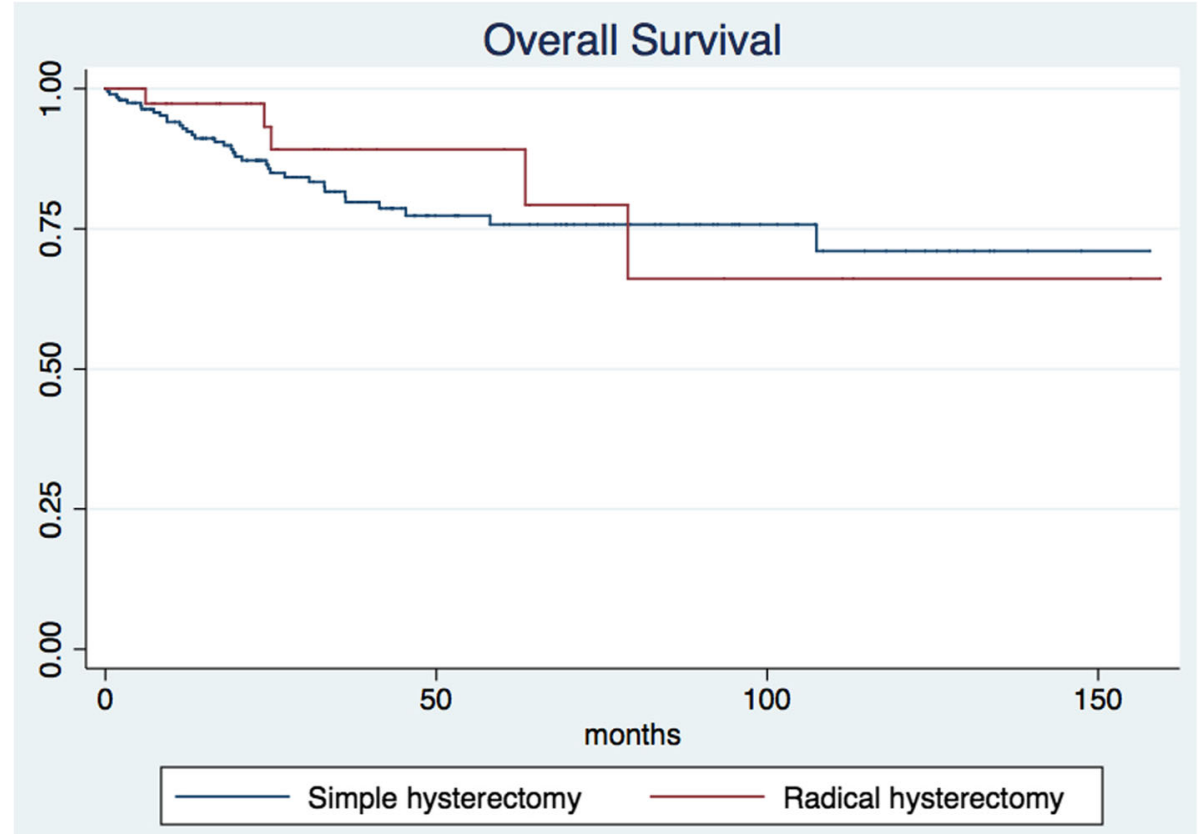

Fig. 2 Overall survival rates of the simple and radical hysterectomy groups $(p=0.513)$ 


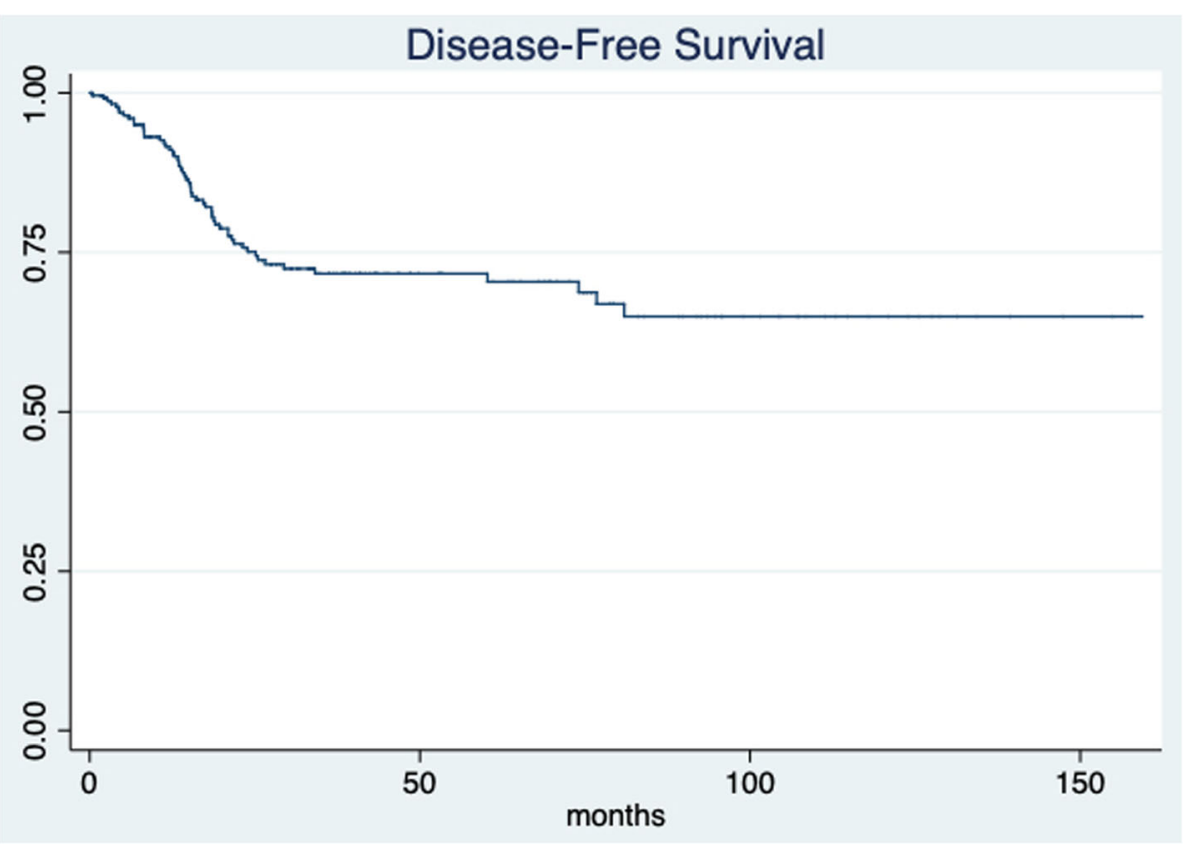

Fig. 3 Disease-free survival rate for all patients

5-year overall survival ( $83.6 \%$ vs. $85.6 \%$ vs. $84 \%$ ) or 5year disease-free survival ( $71.6 \%$ vs. $77.6 \%$ vs. $66.4 \%)$. Furthermore, this study found that the only associated factors were age > 55 years, poor prognostic histologies, grade 3 histology, lymph node disease, and ascites or malignant cytology, similar factors to those found in our study [8]. A case-control study from 2016 compared both hysterectomies in patients with type 1 and stage II endometrial carcinoma but found no difference in the 3-year overall survival $(88.7 \%$ for

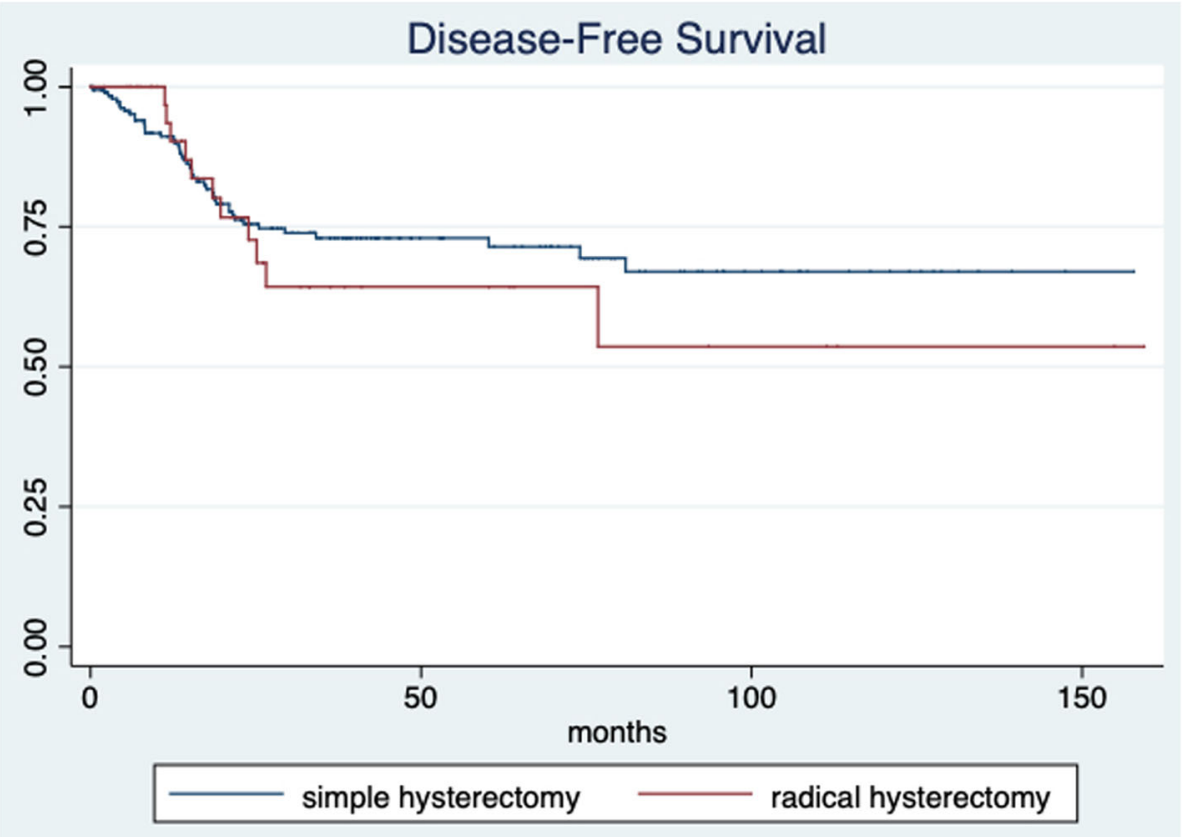

Fig. 4 Disease-free survival rates of the simple and radical hysterectomy groups $(p=0.534)$ 
Table 3 Prognostic factors associated with overall survival in patients with endometrial carcinoma with cervical involvement $(\mathrm{N}=$ 239)

\begin{tabular}{|c|c|c|c|c|c|c|}
\hline & Univa & & & Multiv & & \\
\hline & $H R$ & $95 \% \mathrm{Cl}$ & $p$ & $\mathrm{HR}$ & $95 \% \mathrm{Cl}$ & $p$ \\
\hline Age & 1.01 & $0.98-1.04$ & 0.461 & & & \\
\hline Age $>45$ years & 1.57 & $0.69-3.55$ & 0.284 & & & \\
\hline BMI & 1.01 & $0.95-1.06$ & 0.717 & & & \\
\hline Obesity (BMI > 30) & 1.21 & $0.64-2.28$ & 0.560 & & & \\
\hline $\mathrm{BPH}$ & 2.34 & $1.25-4.43$ & $<0.001$ & 0.94 & $0.38-2.26$ & 0.887 \\
\hline Tumor size, mm & 0.99 & $0.98-1.001$ & 0.587 & & & \\
\hline Tumor size $>4 \mathrm{~cm}$ & 1.01 & $0.38-2.83$ & 0.991 & & & \\
\hline Grade $1-2$ vs. 3-BPH & 4.49 & $2.19-9.22$ & $<0.001$ & 3.39 & $1.16-9.92$ & 0.026 \\
\hline LVI & 2.18 & $1.15-4.12$ & 0.017 & 0.52 & $0.21-1.27$ & 0.152 \\
\hline Myometrial involvement $>50 \%$ & 2.54 & $1.12-5.79$ & 0.026 & 0.97 & $0.35-2.68$ & 0.958 \\
\hline Depth of invasion & 1.01 & $0.97-1.05$ & 0.660 & & & \\
\hline Depth invasion/thickness rate & 0.70 & $0.15-3.18$ & 0.646 & & & \\
\hline Ovarian involvement & 1.69 & $0.83-3.47$ & 0.148 & & & \\
\hline Parametrial involvement & 1.61 & $0.49-5.22$ & 0.432 & & & \\
\hline Uterine serosa involvement & 1.43 & $0.51-4.02$ & 0.495 & & & \\
\hline Pelvic node involvement & 2.03 & $0.96-4.29$ & 0.064 & 1.16 & $0.48-2.78$ & 0.740 \\
\hline Para-aortic node involvement & 1.87 & $0.82-4.28$ & 0.136 & & & \\
\hline Distant disease & 2.38 & $1.04-5.45$ & 0.039 & 0.98 & $0.31-3.18$ & 0.986 \\
\hline Radical hysterectomy & 0.73 & $0.29-1.87$ & 0.515 & & & \\
\hline Radiotherapy & 0.32 & $0.16-0.63$ & 0.001 & 0.12 & $0.04-0.39$ & $<0.001$ \\
\hline Chemotherapy & 2.06 & $1.04-4.07$ & 0.037 & 3.74 & $1.16-12.09$ & 0.027 \\
\hline
\end{tabular}

HR hazard ratio, 95\% CI 95\% confidence interval, BMI body mass index, BPH bad prognostic histology (serous papillary, clear cell, mixed, carcinosarcoma), $L V I$ lymphovascular invasion

simple vs. 94.1\% for radical, $p=0.08$ ) [9]. Likewise, a systematic review published in 2019 found no benefit of radicality for the overall survival (HR 0.92 , 95\% CI $0.72-1.16$ ) or disease-free survival (HR $0.75,95 \%$ CI 0.39-1.42) of patients with stage II disease [12]. Additionally, our study found that radical hysterectomy is associated with bleeding $>500 \mathrm{ml}$, longer surgical times, and intraoperative complications, independent of stage. These results are similar to those found in the GOTIC study: higher surgical time, blood loss, need for transfusion, and urinary retention in the radical hysterectomy group [8].

It is important to note that the type of hysterectomy does not appear to alter adjuvant therapy either. In our study, only 2 patients with cervical involvement had parametrial involvement without other factors of poor prognosis, which warranted a change in their adjuvant treatment. Likewise, a study with 334 patients who underwent radical hysterectomy found that only $8.4 \%$ of patients had parametrial involvement. Although there was a significant difference in the overall survival and disease-free survival in patients with parametrial involvement in this study, this factor was not proven to be an independent prognostic factor (OR 2.12, 95\% CI 0.61-7.81) [6].

Among other findings of our study, a higher percentage of patients who underwent radical hysterectomy had a poor prognostic histology. This finding can be explained by the tumor biology of these histologies, since serous papillary tumors and carcinosarcomas tend to have a greater pelvic spread, which warrants radical surgery to reach optimal cytoreduction without modifying adjuvancy. Furthermore, our study showed that patients with a deeper cervical stromal invasion and a higher ratio of invasion/cervical thickness tended to be those who underwent radical surgeries, probably because they are easier to identify clinically and are prepared to undergo radical surgery from the start. It is also interesting to point out that para-aortic lymphadenectomy is more common in radical hysterectomy, since this procedure is more frequent in patients with poor prognostic histologies and higher grades.

The main weaknesses of our study are its retrospective nature, the low number of patients who underwent 
Table 4 Prognostic factors associated with disease-free survival in patients with endometrial carcinoma with cervical affection $(\mathrm{N}=$ 239)

\begin{tabular}{|c|c|c|c|c|c|c|}
\hline & Unival & & & Multivà & & \\
\hline & $\mathrm{HR}$ & $95 \% \mathrm{Cl}$ & $p$ & $\mathrm{HR}$ & $95 \% \mathrm{Cl}$ & $p$ \\
\hline Age & 1.03 & $1.01-1.05$ & 0.012 & & & \\
\hline Age $>45$ years & 2.91 & $1.24-6.81$ & 0.014 & 5.50 & $0.94-32.00$ & 0.060 \\
\hline BMI & 1.02 & $0.97-1.06$ & 0.578 & & & \\
\hline Obesity (BMI > 30) & 1.29 & $0.78-2.18$ & 0.350 & & & \\
\hline BPH & 2.47 & $1.45-4.19$ & 0.001 & 0.89 & $0.24-3.31$ & 0.867 \\
\hline Tumor size, mm & 0.99 & $0.98-0.99$ & 0.047 & 0.98 & $0.96-0.99$ & 0.031 \\
\hline Tumor size $>4 \mathrm{~cm}$ & 0.72 & $0.34-1.53$ & 0.395 & & & \\
\hline Grade $1-2$ vs. $3-\mathrm{BPH}$ & 3.01 & $1.73-5.23$ & $<0.001$ & 2.92 & $0.62-13.64$ & 0.171 \\
\hline LVI & 2.62 & $1.51-4.52$ & 0.001 & 0.38 & $0.98-1.53$ & 0.98 \\
\hline Myometrial involvement $>50 \%$ & 2.33 & $1.20-4.52$ & 0.012 & 2.64 & $0.52-13.33$ & 0.239 \\
\hline Depth of invasion & 0.97 & $0.92-1.02$ & 0.238 & & & \\
\hline Depth invasion/thickness rate & 0.77 & $0.24-2.49$ & 0.658 & & & \\
\hline Ovarian involvement & 2.67 & $1.53-4.67$ & 0.001 & 0.61 & $0.14-2.61$ & 0.503 \\
\hline Parametrial involvement & 2.91 & $1.24-6.83$ & 0.014 & 13.20 & $0.78-222.04$ & 0.073 \\
\hline Uterine serosa involvement & 2.05 & $0.92-4.54$ & 0.077 & 0.13 & $0.001-1.44$ & 0.096 \\
\hline Pelvic node involvement & 1.66 & $0.88-3.12$ & 0.112 & 2.23 & $0.56-8.84$ & 0.253 \\
\hline Para-aortic node involvement & 1.73 & $0.88-3.39$ & 0.110 & 1.67 & $0.47-5.93$ & 0.426 \\
\hline Distant disease & 4.90 & $2.61-9.21$ & $<0.001$ & 1.22 & $0.28-5.32$ & 0.783 \\
\hline Radical hysterectomy & 1.23 & $0.64-2.38$ & 0.535 & & & \\
\hline Radiotherapy & 0.29 & $0.16-0.54$ & $<0.001$ & 0.116 & $0.02-0.59$ & 0.001 \\
\hline Chemotherapy & 3.36 & $1.77-6.37$ & $<0.001$ & 7.86 & $1.21-51.24$ & 0.031 \\
\hline
\end{tabular}

HR hazard ratio, 95\% Cl 95\% confidence interval, BMI body mass index, BPH bad prognostic histology (serous papillary, clear cell, mixed, carcinosarcoma), $L V I$ lymphovascular invasion

radical hysterectomy compared to simple hysterectomy, the median follow-up time, and the inclusion of multiple histologies. However, this is the first study to evaluate the outcome of these procedures in a Latin American population.

\section{Conclusions}

In patients with endometrial carcinoma with cervical involvement, radical hysterectomy does not improve prognosis or alter adjuvant therapy. However, it is associated with a longer surgical time, risk of intraoperative complications, and bleeding of over $500 \mathrm{ml}$. Prospective studies are needed to better elucidate the role of radical hysterectomy in Latin American patients with endometrial carcinoma.

\section{Abbreviations}

IQR: Interquartile range; OR: Odds ratio; Cl: Confidence interval; SH: Simple hysterectomy; RH: Radical hysterectomy; OS: Overall survival; DFS: Diseasefree survival; HR: Hazard ratio
Authors' contributions

ABM conceived the study and performed the analysis, DCDL assembled the input data and guided the project, $A B J$ wrote the manuscript and analyzed the output data, AGE assembled the input data and guided the project, DIO guided the project and reviewed the manuscript, DP wrote the code and analyzed the output data, LAH critically revised the manuscript and tables, and RASH conceived the study and collected data. All authors read and approved the final manuscript.

Funding

This research did not receive any specific grant from funding agencies in the public, commercial, or not-for-profit sectors.

Availability of data and materials

The datasets generated and/or analyzed during the current study are not publicly available due to hospital policy but are available from the corresponding author on reasonable request.

Ethics approval and consent to participate

This study was approved by the Institutional Review Board (Comité de Investigación y Ética) with approval reference CEI051/16.

Consent for publication

Not applicable.

Competing interests

The authors declare that they have no competing interests. 


\section{Author details}

'Departamento de Ginecología, Instituto Nacional de Cancerología, San Fernando 22, Tlalpan, 14080 Mexico City, Mexico. ${ }^{2}$ Unidad de Investigación Biomédica en Cáncer, Instituto Nacional de Cancerología, Mexico City, Mexico. ${ }^{3}$ Instituto de Investigaciones Biomédicas, Universidad Nacional Autónoma de México, Mexico City, Mexico. ${ }^{4}$ Departamento de Cirugía, Instituto Nacional de Cancerología, Mexico City, Mexico. ${ }^{5}$ Departamento de Informática Biomédica, Faculty of Medicine, Universidad Nacional Autónoma de México, Mexico City, Mexico. ${ }^{6}$ Instituto Nacional de Medicina Genómica, Mexico City, Mexico

Received: 3 March 2020 Accepted: 7 May 2020

Published online: 21 May 2020

\section{References}

1. Kasamatsu T, Onda T, Sawada M, Kato T, Ikeda S. Radical hysterectomy for FIGO stage IIB cervical cancer: clinicopathological characteristics and prognostic evaluation. Gynecol Oncol. 2009;114(1):69-74. https://doi.org/10. 1016/j.ygyno.2009.03.026.

2. Sartori E, Gadducci A, Landoni F, et al. Clinical behavior of 203 stage II endometrial cancer cases: the impact of primary surgical approach and of adjuvant radiation therapy. Int J Gynecol Cancer. 11(6):430-7. http://www. ncbi.nlm.nih.gov/pubmed/11906545. Accessed 17 Oct 2019.

3. Colombo N, Creutzberg C, Amant F, et al. ESMO-ESGO-ESTRO Consensus conference on endometrial cancer: diagnosis, treatment and follow-up. Ann Oncol. 2016;27(1):16-41. https://doi.org/10.1093/annonc/mdv484.

4. Greer BE, Frederick P. NCCN Clinical Practice Guidelines in Oncology Uterine Neoplasms Version 2.2019. Pract Guidel Oncol. 2001:1-48.

5. Miyamoto M, Takano M, Aoyama T, et al. Is modified radical hysterectomy needed for patients with clinical stage I/II endometrial cancers? A historical control study. Oncology. 2016;90(4):179-85. https://doi.org/10.1159/ 000444258.

6. Watanabe $\mathrm{Y}$, Satou T, Nakai $\mathrm{H}$, et al. Evaluation of parametrial spread in endometrial carcinoma. Obstet Gynecol. 2010;116(5):1027-34. https://doi. org/10.1097/AOG.0b013e3181f80a49.

7. Maheshwari A, Gupta S, Prat J. A proposal for updating the staging of endometrial cancer. Int J Gynecol Obstet. 2019;145(2):245-52. https://doi. org/10.1002/ijgo.12789.

8. Takano $\mathrm{M}$, Ochi $\mathrm{H}$, Takei $\mathrm{Y}$, et al. Surgery for endometrial cancers with suspected cervical involvement: is radical hysterectomy needed (a GOTIC study)? Br J Cancer. 2013;109(7):1760-5. https://doi.org/10.1038/bjc.2013.521.

9. Phelippeau J, Koskas M. Impact of radical hysterectomy on survival in patients with stage 2 type 1 endometrial carcinoma: a matched cohort study. Ann Surg Oncol. 2016;23(13):4361-7. https://doi.org/10.1245/s10434016-5372-3.

10. Boente MP, Yordan EL, Mclntosh DG, et al. Prognostic factors and long-term survival in endometrial adenocarcinoma with cervical involvement. Gynecol Oncol. 1993:51(3):316-22. https://doi.org/10.1006/gyno.1993.1297.

11. Colombo N, Creutzberg C, Amant F, et al. ESMO-ESGO-ESTRO consensus conference on endometrial cancer: diagnosis, treatment and follow-up. Radiother Oncol. 2015;117(3):559-81. https://doi.org/10.1016/j. radonc.2015.11.013

12. Liu T, Tu H, Li Y, Liu Z, Liu G, Gu H. Impact of radical hysterectomy versus simple hysterectomy on survival of patients with stage 2 endometrial cancer: a meta-analysis. Ann Surg Oncol. 2019;26(9):2933-42. https://doi.org/ 10.1245/s10434-019-07472-y.

\section{Publisher's Note}

Springer Nature remains neutral with regard to jurisdictional claims in published maps and institutional affiliations.

Ready to submit your research? Choose BMC and benefit from:

- fast, convenient online submission

- thorough peer review by experienced researchers in your field

- rapid publication on acceptance

- support for research data, including large and complex data types

- gold Open Access which fosters wider collaboration and increased citations

- maximum visibility for your research: over $100 \mathrm{M}$ website views per year

At BMC, research is always in progress.

Learn more biomedcentral.com/submissions 